\title{
Commentary
}

\section{The Complexity of Antibody-Dependent Enhancement of Dengue Virus Infection}

\author{
Maria G. Guzman * and Susana Vazquez \\ Department of Virology, PAHO/WHO Collaborating Center for the Study of Dengue and its Vector, \\ “Pedro Kouri” Tropical Medicine Institute of Havana, Cuba; E-Mail: ciipk@ipk.sld.cu \\ * Author to whom correspondence should be addressed; E-Mail: lupe @ipk.sld.cu; \\ Tel.: +53-7-2020450; Fax: +53-7-2046051.
}

Received: 25 October 2010; in revised form: 22 November 2010 / Accepted: 22 November 2010 / Published: 8 December 2010

\begin{abstract}
Antibody-dependent enhancement (ADE) has been proposed as a mechanism to explain dengue hemorrhagic fever (DHF) in the course of a secondary dengue infection. Very recently, Dejnirattisai et al., 2010 [1], published an important article supporting the involvement of anti-prM antibodies in the ADE phenomenon. The complexity of ADE in the context of a secondary dengue infection is discussed here.
\end{abstract}

Keywords: dengue; dengue hemorrhagic fever; prM; ADE; neutralization; cleavage

\section{Introduction}

A rapid increase in dengue reports has been observed in the last three decades. Today, dengue infections are a serious cause of morbidity and mortality in most tropical and subtropical regions of the world: an estimated 50-100 million people are infected annually and over 2.5 billion people live in endemic areas; and more than 100 countries are at risk for dengue transmission. The disease is endemic in Asia, the Pacific, the Americas, Africa and the Middle East [2,3].

Dengue is caused by four antigenically related viruses (DENV 1-4) within the family Flaviviridae, genus Flavivirus. These are transmitted to humans by Aedes mosquito bites, and Aedes aegypti is the main vector. The genome of these enveloped single-strand positive-polarity RNA viruses codes for 
three structural proteins (capsid $\mathrm{C}$, membrane, $\mathrm{M}$, and the envelope, E) and seven non-structural proteins (NS1, NS2A, NS2B, NS3, NS4A, NS4B, NS5) [4].

Two types of virions are recognized: mature extracellular virions contain $\mathrm{M}$ protein, while immature intracellular virions contain prM, which is proteolytically cleaved during maturation to yield M protein.

The envelope of the virus contains the viral surface proteins $\mathrm{E}$ and $\mathrm{M}$. The $\mathrm{E}$ glycoprotein has important functional roles in virus attachment to cells and fusion with membranes, and is the major target for neutralizing antibody. It contains the main epitopes recognized by neutralizing antibodies (virus-specific and cross-reactive epitopes) [5,6]. This protein has three structural and functional domains: domain II contains the internal fusion peptide (responsible for the fusion of flaviviruses to their target cells) and domain III the cellular receptor-binding motifs [7,8]. Domains I and III contain predominantly subcomplex- and type-specific epitopes, whereas domain II contains the major flavivirus group and subgroup cross-reactive epitopes [9-11].

$\mathrm{M}$ protein may be found in two forms. In cell-associated (immature) virions, prM (the precursor of $\mathrm{M}$ protein) is observed, which forms a heterodimer with the $\mathrm{E}$ protein (prM-E heterodimer). Apparently, prM serves as a chaperone for the E protein, protecting it from irreversible inactivation during transport of virions to the cell surface in acidic post-Golgi vesicles $[12,13]$. Through this association, prM participates in the viral assembly and budding into the lumen of the endoplasmic reticulum. Intracellular virions remain non-infectious until release when they are converted to infectious form through the cleavage of prM into the soluble pr peptide and the particle associated $\mathrm{M}$ protein by a host-cell-derived furin-like protease [14].

Uncleaved prM prevents the E protein from undergoing the structural changes that are required for low-pH-induced membrane fusion of DENV. Therefore, fully immature DENV is essentially non-infectious [15]. Depending on the extent of prM cleavage, the extracellular particles may contain varying proportions of prM and $\mathrm{M}$. Levels of around 30\% of prM containing immature particles have been reported in DENV infected cells $[16,17]$. The charged residues surrounding the furin consensus sequence at the prM cleavage junction could partially explain lower or higher cleavage efficiency; in addition, structural differences inherent to flaviviruses at prM junction affect prM cleavability [18].

\section{Dengue Hemorrhagic Fever, Secondary Infection and Antibody-Dependent Enhancement}

Dengue infection can be asymptomatic or present in two clinical forms of illness, dengue fever (DF) and the more severe dengue hemorrhagic fever/dengue shock syndrome (DHF/DSS). Plasma leakage, hemorrhage and thrombocytopenia characterize DHF/DSS [19,20].

Single-serotype natural infections result in lifelong immunity to the infecting serotype but only short-term cross-protection against heterotypic serotypes [21]. The humoral response to dengue infection is important for controlling infection and virus dissemination. Despite antigenic relatedness of viruses in the dengue complex, two or more serotypes may sequentially infect one individual. Specific neutralizing IgG antibody against the infecting DENV lasts decades, while cross-reactive neutralizing activity declines over time [22,23]. Preliminary reports also suggest that in human beings there is a continuous selection process of populations of dengue-virus neutralizing-antibodies with increasing homologous reactivity and concurrent decrease in heterotypic cross reactions [24]. 
Early studies in Thailand recognized that DHF/DSS peaked in two populations: first-time infected infants born to dengue-immune mothers and children who had experienced a mild or asymptomatic dengue infection and become secondarily infected by a different dengue serotype [25,26]. These studies suggested that DHF/DSS is 15-80 times more frequent in secondary infections than in primary ones, and that up to $99 \%$ of DHF cases reveal heterotypic antibodies to the dengue serotype causing the DHF [27].

These first observations were confirmed in a different setting. The DENV 2 epidemic of 1981 (preceded by a mild epidemic of DENV 1 in 1977) reported in Cuba, supported secondary infection as a main risk factor for the severe forms of dengue infection. In this epidemic of more than 300,000 cases, 10,000 severe and very severe cases and 158 fatalities (101 children), secondary infection in the sequence DENV 1/DENV 2 was demonstrated in 98\% of the DHF/DSS cases [28-30]. In addition, DHF/DSS did not occur in children of 1-2 years. They were born after the 1977 epidemic and, consequently, in 1981, they were at risk only of primary DENV infection [29]. More than 20 years after the DENV 1 epidemic, secondary infection as a main risk factor for DHF/DSS was confirmed again in the Cuban epidemics of 1997 (DENV 2) and 2001-02 (DENV 3) [31-35].

To explain the association of secondary infection to severe illness, Antibody-Dependent Enhancement (ADE) was proposed as the immune system's mechanism to enhance viral pathogenesis. ADE has been described for several viruses including DENVs, measured by in vitro enhancement of cell infection [36-38]. Also, monkeys passively immunized concurrently with a DENV infection developed a higher viremia than control animals [39]. More recently, Goncalvez et al. [40] demonstrated a significant increase of DENV 4 viremia titers in monkeys passively immunized with transferred dilutions of an anti-dengue humanized monoclonal antibody [40].

In humans, indirect evidence of ADE has been reported. ADE was observed in vitro in sera from mothers whose infants developed DHF after a primary dengue infection [41]. This study demonstrated that maternal antibody to DENV declines at a constant rate and passes in time through three functional states: neutralization, enhancing virus growth and antibody degradation. This early study suggested that as anti-dengue antibody to a first infection wanes, some individuals will experience an interval during which their antibody level will drop below its protective capacity, acquiring the power to enhance infection. In another study, Kliks et al. [42] reported that undiluted pre-infection sera from children who developed DHF were more likely to show enhancement of the dengue virus infection than pre-infection sera of children with an asymptomatic secondary infection.

Evidence suggests that enhancing and cross-reactive neutralizing antibodies regulate dengue epidemics and disease severity. In this sense, epidemiological and serological observations made during the Cuban dengue epidemics support the role of secondary infection and ADE even 20 or more years after primary dengue infection. A marked increase in severity associated with the longer of the two intervals (20 years versus four years) between an initial DENV1 infection and a secondary DENV 2 (Asian genotype) infection has been reported [43]. In addition, some sequences of infection such as DENV 1 followed by DENV 2, and DENV 1 followed by DENV 3 have been associated with greater disease severity $[44,45]$. 


\section{The Antibody-Dependent Enhancement Phenomenon}

ADE occurs when antibody-virus complexes are internalized into cells via Fc $\gamma$ Rs resulting in infection of a higher number of target cells, which may lead to higher viral production. Cross-reactive antibodies lacking neutralizing activity are induced during a primary dengue infection. In secondary infection, these antibodies bind to the second infecting virus. Increased viral production has typically been interpreted to be the result of an increased number of infected Fc $\gamma$-R-bearing cells and possibly the result of an accelerated rate of internalization and cell infection by immune-complexes [46-48]. A higher viremia in infected patients and consequent greater severity has been hypothesized [49]. Studies reported by Vaughn et al. and Libraty et al. observed a higher viremia and NS1 antigenemia in children with DHF than in those with DF [50,51]. Also in Taiwanese patients it was observed that dengue RNA titers even after defervescence, correlated with disease severity [52]. In a more recent study, Cameron et al. reported heterogeneity in viremia and NS1 antigenemia in Vietnamese infants with DHF in the course of their primary DENV infection; however these determinations were made at the time of hospital admission. They also found that these infants experienced DHF when the maternally-derived neutralizing antibody titer had declined to $<1: 20$ [53].

A complementary mechanism to higher viremia explaining disease severity as a consequence of ADE may be that FcyR-mediated entry suppresses the antiviral immune response. An in vitro study with Ross River virus showed that viral entry via the FcR pathway could suppress antiviral genes and enhance IL-10 production, while entry via the normal mechanism does not change the antiviral environment [54]. In the case of dengue, it has been reported that infection of THP-1 cells via FcR also suppresses transcription and production of IL-12, IFN $\gamma, \mathrm{TNF} \alpha$ and NO, but enhances the expression of anti-inflammatory cytokines [55] with a milieu change favorable to viral replication. These observations suggest that ADE of DENV infection not only facilitates the virus entry process but also could modify innate and adaptive intracellular antiviral mechanisms [55].

Studies using monoclonal antibodies have demonstrated that enhancing antibodies are directed to $\mathrm{E}$ and prM proteins [56]. Although both proteins seem to be involved in neutralization and the ADE mechanism, more studies have been designed to evaluate the role of E protein. Greater understanding of the antibody-neutralization mechanisms could shed light on their likelihood of promoting ADE.

\section{The Neutralization Mechanism}

Flavivirus neutralization is a multiple-hit phenomenon requiring engagement by more than one antibody. Neutralization occurs when the number of antibodies bound to an individual virion exceeds a required threshold, antibody affinity and accessibility of epitopes on virus particles playing an important role [57]. Neutralizing antibodies directed mostly to E protein inhibit viral attachment, internalization and/or replication within the cell [58]. These E-specific antibodies appear to be pivotal, mediating homologous protection against dengue reinfection; however, in mice, prM vaccine has also been shown to protect against the lethal DENV challenge [59].

Neutralization at low occupancy requires lower antibody concentrations and can occur with lower-affinity antibodies, while those antibodies specific to poorly accessible epitopes require relatively high concentrations. Most epitopes have the capacity to elicit antibodies capable of promoting ADE [60]; however, antibodies specific to poorly accessible epitopes are more likely to 
promote ADE over a wide range of concentrations [61,62]. Recently, Lok et al. [63] showed that a partially occluded epitope may become available to antibody binding under certain conditions, suggesting that the virus is in dynamic motion making hidden epitopes briefly available [63].

Despite the large body of work with mouse monoclonal antibodies, little has been done to characterize the binding properties of human dengue immune sera and to understand the relationship between human antibody binding, neutralization and ADE [64]. Recent studies have proposed that the major cross-reactive and serotype-specific neutralizing epitopes targeted by human immune sera are inter-domain epitopes and/or located outside of domain III of E protein [40,65]. Wahala et al. observed that, unexpectedly, domain III-binding antibodies play a minor role in DENV neutralization. In addition, in another report these authors suggest that type-specific epitopes on domain III are not conserved between strains of DENV3 [66]. Previous investigations support large differences in neutralization titers when comparing different genotypes of the same virus $[67,68]$.

\section{Potential Role of Immature DENV in Antibody-Dependent Enhancement}

Recently, Dejnirattisai et al. [1] generated a panel of human monoclonal antibodies to DENV. They observed that (a) antibodies to prM were a major component of the response, highly cross-reactive among the dengue serotypes, and (b) these antibodies have potent ADE activity and low neutralization capacity. Considering these results, the authors propose that partial cleavage of prM reduces antigen density availability for viral neutralization, leaving the viruses susceptible to ADE by antibody to prM.

Previously, a host-protective effect of anti-prM was reported for DENV; however, how these antibodies would exert their effect was not clear [18,59,69-71]. It has been proposed that weak neutralization of dengue infectivity by some anti prM monoclonal antibodies and anti-prM peptide sera could be due to their cross-reactivity with E protein [18,70,71]. However, similar levels of enhancing activity by strongly enhancing anti-E monoclonal antibodies have been previously reported [56,72]. Some studies report enhancement of infection presumably due to the presence of uncleaved prM in virus preparations, but also with DENV particles containing high levels of prM after cell treatment with chloroquine [72,73]. Apparently, infection enhancement and lack of potent neutralization are common properties of anti-prM antibodies, suggesting that prM constitutes another target for infection-enhancing antibodies but also that extracellular dengue virions containing prM could be infectious [18].

Previous studies have shown that immature particles are non-infectious, since the presence of prM obstructs the low-pH-induced conformational changes in the E protein required for membrane fusion of the virus [15,74]. However, very recently, Rodenhuis-Zybert et al. [75] showed that fully immature dengue particles become highly infectious when interacting with prM antibodies. They showed that lack of infectivity of immature particles in the absence of antibodies was related to inefficient binding of immature virions to cell surfaces, but if binding is facilitated through anti-prM antibodies, immature particles become highly infectious, presumably due to efficient intracellular processing of prM to $\mathrm{M}$ by furin activity within the target cell. These antibodies facilitate efficient binding and cell entry by immature particles into Fc-R- expressing cells [75].

Together, these observations suggest that immature viral particles have the potential to be highly infectious and hence may contribute to development of the severe disease during secondary 
infection [75]. Consequently, it is important to define the possible in vivo effects of maintaining prM on the virion surface but also the viral and host factors involved in the efficiency of prM cleavage. It has been suggested that alteration of furin target sequence in the prM junction can affect virus export [76]. Also, several studies have suggested that the multiplication of flaviviruses is not self-reliant and that the viruses subvert cellular proteins to become part of their replication strategy $[77,78]$.

Of interest is that Dejnirattisai et al. [1] found that antibodies to prM were a major component of the anti-dengue response. Previous reports recognized that the main response is directed to E protein, but also support that anti-prM antibodies are generated during dengue infection in humans [79-81]. It cannot be excluded that these apparently dissimilar observations depend on the characteristics of the tested samples and the employed methodologies.

CryoEM images have shown that WNV and DENV preparations contain a mixture of immature, partially mature and mature viral particles, most likely due to incomplete processing by furin during maturation [82]. Cherrier et al. showed that an epitope within the fusion loop of WNV E protein is largely inaccessible in mature virions but that a cross-reactive fusion-loop antibody with low neutralization activity binds preferentially to the spikes in immature virions [82]. In a secondary infection, these antibodies may promote infection through ADE by augmenting attachment and/or entry of partially immature virions. The fact that an antibody neutralizes infectivity by binding to an immature virion supports the hypothesis that hybrid mature/immature particles can contribute to virus infectivity and pathogenesis [82]. These observations can also be extended to anti prM antibody.

Figure 1 shows viral populations and anti-E and -prM antibodies involved in neutralization and ADE of DENV infection.

Figure 1. Schematic representation of viral populations and anti-E and anti-prM antibodies involved in neutralization and ADE mechanism. Immature $(O)$, partially mature $(\theta)$, mature $(O)$ viral particles, neutralizing anti-E antibodies $(Y)$, cross-reactive non-neutralizing anti-E antibodies $(Y)$ and cross reactive anti-prM antibodies $(Y)$.

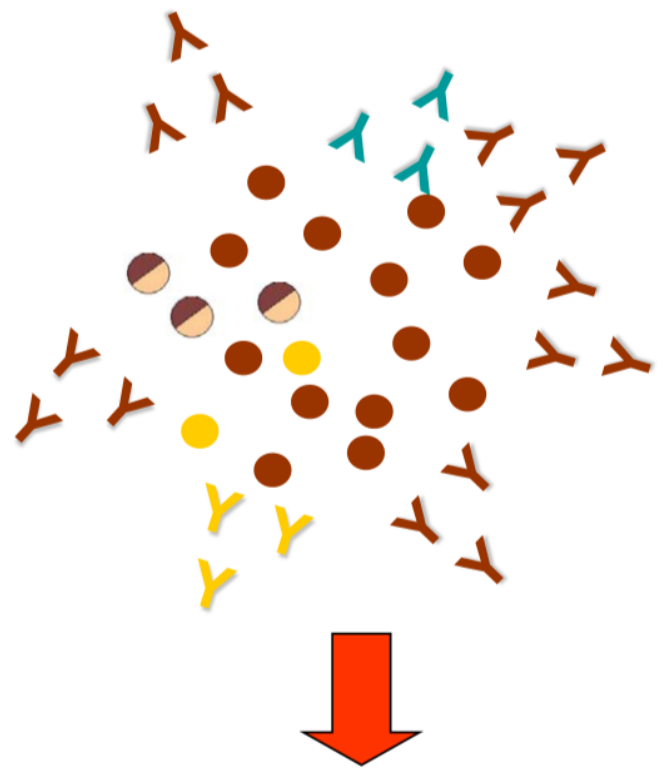

Neutralization

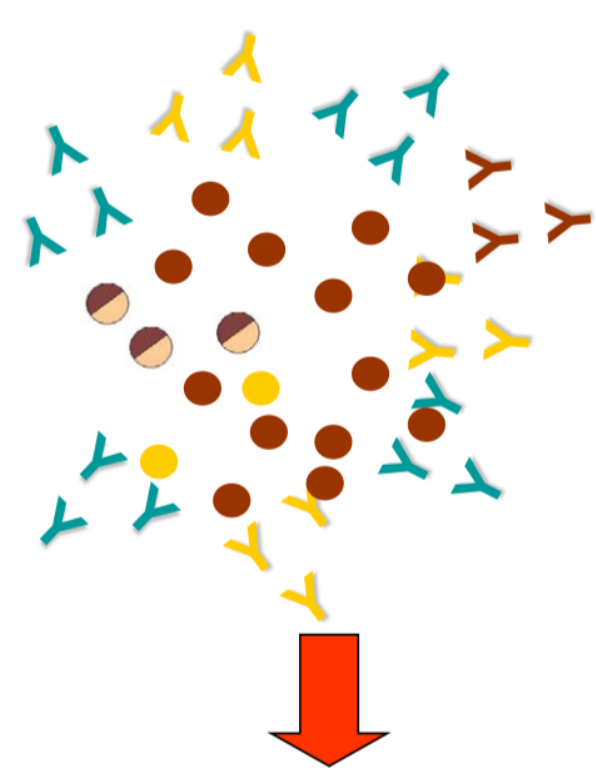

ADE 


\section{Conclusions}

DHF/DSS is the result of the interaction of several factors in which the viral and host characteristics are important [44,83]. Some DENV genotypes have the potential to produce DHF [84]. In addition, host factors are of importance: these include age (children at higher risk than adults), ethnicity (white people at higher risk than black people), chronic diseases (bronchial asthma, diabetes mellitus, sickle cell anemia), nutritional status, sex and the individual's genetic composition (allelic variants of genes that encode cellular receptors such as DC-SIGN and Fc $\gamma$ RIIA, Vitamin D receptor as well as molecules involved in the antigen recognition, HLA, and cytokines have also been associated with higher or lower risk of DHF) [85-91]. However, secondary infection is considered the main risk factor for disease severity.

The dengue antibody somehow modulates subsequent infection with an enhancing or neutralizing role that up- or down-regulates dengue infection of mononuclear phagocytes (Figure 1) [92]. Consistent with current evidence and considering ADE as a central mechanism, a working hypothesis of dengue pathogenesis suggests that DHF/DSS during a secondary infection is the result of antibody-enhanced infection of mononuclear phagocytes. Immune complex infection suppresses cellular immune responses, increasing intracellular infection and generating inflammatory cytokines and chemokines that together contribute to the development of severe disease [48].

Concern over ADE and its role in DHF/DSS suggest the necessity of a tetravalent dengue vaccine stimulating a balanced and long-lasting immune response to the four serotypes. The elegant work published by Dejnirattisai et al. [1] adds new information to our knowledge about ADE, calling attention to the complexity of this phenomenon [1]. More research is needed to elucidate ADE's molecular mechanisms, particularly factors influencing the final outcome of the interaction among the virus, antibody and permissive cells. Among the issues meriting careful study are the interaction of anti-prM and -E antibodies with the infecting virus to neutralize or enhance infection, the factors determining the ratio of immature/mature virion particles, the influence of ADE complement levels, and the interaction with Fc-receptors [93-96].

\section{Acknowledgments}

The authors thank Gail Reed, Didye Ruiz and Olaf Horstick for their technical support as well as J.M. Smit for her useful comments and suggestions.

\section{References and Notes}

1. Dejnirattisai, W.; Jumnainsong, A.; Onsirisakul, N.; Fitton, P.; Vasanawathana, S.; Limpitikul, W.; Puttikhunt, C.; Edwards, C.; Duangchinda, T.; Supasa, S.; et al. Cross-reacting antibodies enhance dengue virus infection in humans. Science 2010, 328, 745-748.

2. Guzman, M.G.; Kouri, G. Dengue: An update. Lancet Infect. Dis. 2002, 2, 33-42.

3. Gubler, D.J. Epidemic dengue/dengue hemorrhagic fever as a public health, social and economic problem in the 21st century. Trends Microbiol. 2002, 10, 100-103.

4. Beasley, D.W.C.; Barrett, A.D.T. The Infectious Agent. In Dengue; Pasvol, G., Hoffman, S.L., Eds.; Imperial College Press: Covent Garden, London, UK, 2008; Volume 5, pp. 29-73. 
5. Guirakhoo, F.; Heinz, F.X.; Mandl, C.W.; Holzmann, H.; Kunz, C. Fusion activity of flaviviruses: Comparison of mature and immature (prM-containing) tick-borne encephalitis virions. J. Gen. Virol. 1991, 72, 1323-1330.

6. Putnak, R.; Feighny, R.; Burrous, J.; Cochran, M.; Hackett, C.; Smith, G.; Hoke, C. Dengue-1 virus envelope glycoprotein gene expressed in recombinant baculovirus elicits virus-neutralizing antibody in mice and protects them from virus challenge. Am. J. Trop. Med. Hyg. 1991, 45, 159-167.

7. Crill, W.D.; Roehrig, J.T. Monoclonal antibodies that bind to domain III of dengue virus E glycoprotein are the most efficient blockers of virus adsorption to Vero cells. J. Virol. 2001, 75, 7769-7773.

8. Modis, Y.; Ogata, S.; Clements, D.; Harrison, S.C. A ligand-binding pocket in the dengue virus envelope glycoprotein. Proc. Natl. Acad. Sci. U. S. A. 2003, 100, 6986-6991.

9. Mandl, C.W.; Guirakhoo, F.; Holzmann, H.; Heinz, F.X.; Kunz, C. Antigenic structure of the flavivirus envelope protein $\mathrm{E}$ at the molecular level, using tick-borne encephalitis virus as a model. J. Virol. 1989, 63, 564-571.

10. Rey, F.A.; Heinz, F.X.; Mandl, C.; Kunz, C.; Harrison, S.C. The envelope glycoprotein from tick-borne encephalitis virus at 2 A resolution. Nature 1995, 375, 291-298.

11. Roehrig, J.T.; Bolin, R.A.; Kelly, R.G. Monoclonal antibody mapping of the envelope glycoprotein of the dengue 2 virus, Jamaica. Virology 1998, 246, 317-328.

12. Guirakhoo, F.; Bolin, R.A.; Roehrig, J.T. The Murray Valley encephalitis virus prM protein confers acid resistance to virus particles and alters the expression of epitopes within the R2 domain of E glycoprotein. Virology 1992, 191, 921-931.

13. Lindenbach, B.D.; Rice, C.M. Flaviviridae: The Viruses and Their Replication. In Fields Virology, Knippe, D.M., Howley, P.M.; Lippincott Willians \& Wilkins: Philadelphia, USA, 2001; Volume 1, pp. 991-1042.

14. Thomas, G. Furin at the cutting edge: From protein traffic to embryogenesis and disease. Nat. Rev. Mol. Cell Biol. 2002, 10, 753-766.

15. Zybert, I.A.; van der Ende-Metselaar, H.; Wilschut, J.; Smit, J.M. Functional importance of dengue virus maturation: Infectious properties of immature virions. J. Gen. Virol. 2008, 89, 3047-3051.

16. Elshuber, S.; Mandl, C.W. Resuscitating mutations in a furin cleavage-deficient mutant of the flavivirus tick-borne encephalitis virus. J. Virol. 2005, 79, 11813-11823.

17. Heinz, F.X.; Stiasny, K.; Puschner Auer, G.; Holzmann, H.; Allison, S.L.; Mandl, C.W.; Kunz, C. Structural changes and functional control of the tick-borne encephalitis virus glycoprotein E by the heterodimeric association with protein prM. Virology 1994, 198, 109-117.

18. Sittisombut, N.; Keelapang, P.; Malasit, P. Functional role of prM glycoprotein in dengue virus replication. In Molecular Biology of the Flavivirus, Kalitzky, M., Borowski, P.; Horizon Bioscience: Norfolk, UK, 2006; p. 170.

19. WHO. Clinical Diagnosis. In Dengue Hemorrhagic Fever. Diagnosis, treatment, prevention and control, 2nd ed.; TDR/WHO; Geneva, Switzerland, 1997; pp. 1-84.

20. WHO. Strengthening implementation of the global strategy for dengue/dengue hemorrhagic fever prevention and control. Geneva, Switzerland, 1999; pp. 1-19. 
21. Sabin, A.B. Research on dengue during World War II. Am. J. Trop. Med. Hyg. 1952, 1, 30-50.

22. Halstead, S.B. Etiologies of the experimental dengues of Siler and Simmons. Am. J. Trop. Med. Hyg. 1974, 23, 974-982.

23. Vaughn, D.W.; Scherer, J.M.; Sun, W. Resistance to infection. In Dengue; Pasvol, G., Hoffman, S.L., Eds.; Imperial College Press: Covent Garden, London, UK, 2008; Volume 5, pp. 123-169.

24. Guzman, M.G.; Alvarez, M.; Rodriguez-Roche, R.; Bernardo, L.; Montes, T.; Vazquez, S.; Morier, L.; Alvarez, A.; Gould, E.A.; Kouri, G.; et al. Neutralizing antibodies after infection with dengue 1 virus. Emerg. Infect. Dis. 2007, 13, 282-286.

25. Halstead, S.B. Observations related to pathogensis of dengue hemorrhagic fever. VI. Hypotheses and discussion. Yale J. Biol. Med. 1970, 42, 350-362.

26. Halstead, S.B.; Nimmannitya, S.; Cohen, S.N. Observations related to pathogenesis of dengue hemorrhagic fever. IV. Relation of disease severity to antibody response and virus recovered. Yale J. Biol. Med. 1970, 42, 311-328.

27. Halstead, S.B. Immune enhancement of viral infection. Prog. Allergy 1982, 31, 301-364.

28. Kouri, G.P.; Guzman, M.G.; Bravo, J.R.; Triana, C. Dengue haemorrhagic fever/dengue shock syndrome: Lessons from the Cuban epidemic, 1981. Bull. World Health Organ. 1989, 67, 375-380.

29. Guzman, M.G.; Kouri, G.; Martinez, E.; Bravo, J.; Riveron, R.; Soler, M.; Vazquez, S.; Morier, L. Clinical and serologic study of Cuban children with dengue hemorrhagic fever/dengue shock syndrome (DHF/DSS). Bull. Pan. Am. Health Organ. 1987, 21, 270-279.

30. Diaz, A.; Kouri, G.; Guzman, M.G.; Lobaina, L.; Bravo, J.; Ruiz, A.; Ramos, A.; Martinez, R. Description of the clinical picture of dengue hemorrhagic fever/dengue shock syndrome (DHF/DSS) in adults. Bull. Pan. Am. Health Organ. 1988, 22, 133-144.

31. Guzman, M.G.; Kouri, G.; Valdes, L.; Bravo, J.; Alvarez, M.; Vazquez, S.; Delgado, I.; Halstead, S.B. Epidemiologic studies on Dengue in Santiago de Cuba, 1997. Am. J. Epidemiol. 2000, 152, 793-799; discussion 804.

32. Valdes, L.; Guzman, M.G.; Kouri, G.; Delgado, J.; Carbonell, I.; Cabrera, M.V.; Rosario, D.; Vazquez, S. [Epidemiology of dengue and hemorrhagic dengue in Santiago, Cuba 1997]. Rev. Panam. Salud Publica 1999, 6, 16-25.

33. Kouri, G.; Guzman, M.G.; Valdes, L.; Carbonel, I.; del Rosario, D.; Vazquez, S.; Laferte, J.; Delgado, J.; Cabrera, M.V. Reemergence of dengue in Cuba: A 1997 epidemic in Santiago de Cuba. Emerg. Infect. Dis. 1998, 4, 89-92.

34. Pelaez, O.; Guzmán, M.G.; Kourí, G.; Pérez, R.; Martín, J.L.S.; Vázquez, S.; Rosario, D.; Mora, R.; Quintana, I.; Bisset, J.; et al. Dengue 3 epidemic in Havana, 2001. Emerg. Infect. Dis. 2004, 10, 219-222.

35. Gonzalez, D.; Castro, O.; Perez, J.; Martinez, E.; Vazquez, S.; Rosario, D.; Cancio, R.; Guzman, M.G. Classical dengue hemorrhagic fever resulting from two dengue infections spaced 20 years or more apart: Havana, Dengue 3 epidemic, 2001-2002. Int. J. Infect. Dis. 2005, 9, 280-285.

36. Ghiasi, H.; Perng, G.C.; Nesburn, A.; Wechsler, S. Antibody-dependent enhancement of HSV-1 infection by anti-gK sera. Virus Res. 2000, 68, 137-144. 
37. Girn, J.; Kavoosi, M.; Chantler, J. Enhancement of coxsackievirus B3 infection by antibody to a different coxsackievirus strain. J. Gen. Virol. 2002, 83, 351-358.

38. Hober, D.; Chehadeh, W.; Bouzidi, A.; Wattré, P. Antibody-dependent enhancement of coxsackievirus B4 infectivity of human peripheral blood mononuclear cells results in increased interferon-alpha synthesis. J. Infect. Dis. 2001, 184, 1098-1108.

39. Halstead, S.B. In vivo enhancement of dengue virus infection in rhesus monkeys by passively transferred antibody. J. Infect. Dis. 1979, 140, 527-533.

40. Goncalvez, A.P.; Engle, R.E.; St Claire, M.; Purcell, R.H.; Lai, C.J. Monoclonal antibodymediated enhancement of dengue virus infection in vitro and in vivo and strategies for prevention. Proc. Natl. Acad. Sci. U. S. A. 2007, 104, 9422-9427.

41. Kliks, S.C.; Nimmanitya, S.; Nisalak, A.; Burke, D.S. Evidence that maternal dengue antibodies are important in the development of dengue hemorrhagic fever in infants. Am. J. Trop. Med. Hyg. 1988, 38, 411-419.

42. Kliks, S.C.; Nisalak, A.; Brandt, W.E.; Wahl, L.; Burke, D.S. Antibody-dependent enhancement of dengue virus growth in human monocytes as a risk factor for dengue hemorrhagic fever. Am. J. Trop. Med. Hyg. 1989, 40, 444-451.

43. Guzman, M.G.; Kouri, G.; Valdes, L.; Bravo, J.; Vazquez, S.; Halstead, S.B. Enhanced severity of secondary dengue-2 infections: Death rates in 1981 and 1997 Cuban outbreaks. Rev. Panam. Salud Publica 2002, 11, 223-227.

44. Guzman, M.G.; Kouri, G. Dengue haemorrhagic fever integral hypothesis: Confirming observations, 1987-2007. Trans. R. Soc. Trop. Med. Hyg. 2008, 102, 522-523.

45. Alvarez, M.; Rodriguez-Roche, R.; Bernardo, L.; Vazquez, S.; Morier, L.; Gonzalez, D.; Castro, O.; Kouri, G.; Halstead, S.B.; Guzman, M.G. Dengue Hemorrhagic Fever Caused by Sequential Dengue 1-3 Virus Infections over a Long Time Interval: Havana Epidemic, 20012002. Am. J. Trop. Med. Hyg. 2006, 75, 1113-1117.

46. Gollins, S.W.; Porterfield, J.S. Flavivirus infection enhancement in macrophages: Radioactive and biological studies on the effect of antibody on viral fate. J. Gen. Virol. 1984, 65, 1261-1272.

47. Gollins, S.W.; Porterfield, J.S. Flavivirus infection enhancement in macrophages: An electron microscopic study of viral cellular entry. J. Gen. Virol. 1985, 66, 1969-1982.

48. Halstead, S.B. Pathophysiology. In Dengue; Pasvol, G., Hoffman, S.L., Eds.; Imperial College Press: Covent Garden, London, UK, 2008; Volume 5, pp. 285-326.

49. Stephenson, J.R. Understanding dengue pathogenesis: Implications for vaccine design. Bull. World Health Organ. 2005, 83, 308-314.

50. Vaughn, D.W.; Green, S.; Kalayanarooj, S.; Innis, B.L.; Nimmannitya, S.; Suntayakorn, S.; Endy, T.P.; Raengsakulrach, B.; Rothman, A.L.; Ennis, F.A.; et al. Dengue viremia titer, antibody response pattern, and virus serotype correlate with disease severity. J. Infect. Dis. 2000, 181, 2-9.

51. Libraty, D.H.; Young, P.R.; Pickering, D.; Endy, T.P.; Kalayanarooj, S.; Green, S.; Vaughn, D.W.; Nisalak, A.; Ennis, F.A.; Rothman, A.L. High circulating levels of the dengue virus nonstructural protein NS1 early in dengue illness correlate with the development of dengue hemorrhagic fever. J. Infect. Dis. 2002, 186, 1165-1168. 
52. Wang, W.K.; Chao, D.Y.; Kao, C.L.; Wu, H.C.; Liu, Y.C.; Li, C.M.; Lin, S.C.; Ho, S.T.; Huang, J.H.; King, C.C. High levels of plasma dengue viral load during defervescence in patients with dengue hemorrhagic fever: Implications for pathogenesis. Virology 2003, 305, 330-338.

53. Cameron, B.; Galbraith, S.; Zhang, Y.; Davenport, T.; Vollmer-Conna, U.; Wakefield, D.; Hickie, I.; Dunsmuir, W.; Whistler, T.; Vernon, S.; et al. Gene expression correlates of postinfective fatigue syndrome after infectious mononucleosis. J. Infect. Dis. 2007, 1, 56-66.

54. Lidbury, B.A.; Mahalingam, S. Specific ablation of antiviral gene expression in macrophages by antibody-dependent enhancement of Ross River virus infection. J. Virol. 2000, 74, 8376-8381.

55. Chareonsirisuthigul, T.; Kalayanarooj, S.; Ubol, S. Dengue virus (DENV) antibody-dependent enhancement of infection upregulates the production of anti-inflammatory cytokines, but suppresses anti-DENV free radical and pro-inflammatory cytokine production, in THP-1 cells. J. Gen. Virol. 2007, 88, 365-375.

56. Henchal, E.A.; McCown, J.M.; Burke, D.S.; Seguin, M.C.; Brandt, W.E. Epitopic analysis of antigenic determinants on the surface of dengue-2 virions using monoclonal antibodies. Am. J. Trop. Med. Hyg. 1985, 34, 162-169.

57. Pierson, T.C.; Diamond, M.S. Molecular mechanisms of antibody-mediated neutralisation of flavivirus infection. Expert Rev. Mol. Med. 2008, 10, e12.

58. King, N.J.; Getts, D.R.; Getts, M.T.; Rana, S.; Shrestha, B.; Kesson, A.M. Immunopathology of flavivirus infections. Immunol. Cell Biol. 2007, 85, 33-42.

59. Kaufman, B.M.; Summers, P.L.; Dubois, D.R.; Cohen, W.H.; Gentry, M.K.; Timchak, R.L.; Burke, D.S.; Eckels, K.H. Monoclonal antibodies for dengue virus prM glycoprotein protect mice against lethal dengue infection. Am. J. Trop. Med. Hyg. 1989, 41, 576-580.

60. Pierson, T.C. Modeling Antibody-Enhanced Dengue Virus Infection and Disease in Mice: Protection or Pathogenesis? Cell Host Microbe 2007, 7, 85-86.

61. Roehrig, J.T.; Mathews, J.H.; Trent, D.W. Identification of epitopes on the E glycoprotein of Saint Louis encephalitis virus using monoclonal antibodies. Virology 1983, 128, 118-126.

62. Throsby, M.; Geuijen, C.; Goudsmit, J.; Bakker, A.Q.; Korimbocus, J.; Kramer, R.A.; Clijsters-van der Horst, M.; de Jong, M.; Jongeneelen, M.; Thijsse, S.; et al. Isolation and characterization of human monoclonal antibodies from individuals infected with West Nile Virus. J. Virol. 2006, 80, 6982-6992.

63. Lok, S.M.; Kostyuchenko, V.; Nybakken, G.E.; Holdaway, H.A.; Battisti, A.J.; Sukupolvi-Petty, S.; Sedlak, D.; Fremont, D.H.; Chipman, P.R.; Roehrig, J.T.; et al. Binding of a neutralizing antibody to dengue virus alters the arrangement of surface glycoproteins. Nat. Struct. Mol. Biol. 2008, 15, 312-317.

64. Schieffelin, J.S.; Costin, J.M.; Nicholson, C.O.; Orgeron, N.M.; Fontaine, K.A.; Isern, S.; Michael, S.F.; Robinson, J.E. Neutralizing and non-neutralizing monoclonal antibodies against dengue virus E protein derived from a naturally infected patient. Virol. J. 2010, 7, 28.

65. Wahala, W.M.; Kraus, A.A.; Haymore, L.B.; Accavitti-Loper, M.A.; de Silva, A.M. Dengue virus neutralization by human immune sera: Role of envelope protein domain III-reactive antibody. Virology 2009, 392, 103-113. 
66. Wahala, W.M.; Donaldson, E.F.; de Alwis, R.; Accavitti-Loper, M.A.; Baric, R.S.; de Silva, A.M. Natural strain variation and antibody neutralization of dengue serotype 3 viruses. PLoS Pathog. 2010, 6, e1000821.

67. Blaney, J.E., Jr.; Matro, J.M.; Murphy, B.R.; Whitehead, S.S. Recombinant, live-attenuated tetravalent dengue virus vaccine formulations induce a balanced, broad, and protective neutralizing antibody response against each of the four serotypes in rhesus monkeys. J. Virol. 2005, 79, 5516-5528.

68. Alvarez, M.; Pavon-Oro, A.; Rodriguez-Roche, R.; Bernardo, L.; Morier, L.; Sanchez, L.; Alvarez, A.M.; Guzman, M.G. Neutralizing antibody response variation against dengue 3 strains. J. Med. Virol. 2008, 80, 1783-1789.

69. Bray, M.; Lai, C.J. Dengue virus premembrane and membrane proteins elicit a protective immune response. Virology 1991, 185, 505-508.

70. Falconar, A.K. Identification of an epitope on the dengue virus membrane (M) protein defined by cross-protective monoclonal antibodies: Design of an improved epitope sequence based on common determinants present in both envelope (E and M) proteins. Arch. Virol. 1999, 144, 2313-2330.

71. Vazquez, S.; Guzman, M.G.; Guillen, G.; Chinea, G.; Perez, A.B.; Pupo, M.; Rodriguez, R.; Reyes, O.; Garay, H.E.; Delgado, I.; et al. Immune response to synthetic peptides of dengue prM protein. Vaccine 2002, 20, 1823-1830.

72. Randolph, V.B.; Winkler, G.; Stollar, V. Acidotropic-amines inhibit proteolytic processing of flavivirus prM protein. Virology 1990, 174, 450-458.

73. Huang, K.J.; Yang, Y.C.; Lin, Y.S.; Huang, J.H.; Liu, H.S.; Yeh, T.M.; Chen, S.H.; Liu, C.C.; Lei, H.Y. The dual-specific binding of dengue virus and target cells for the antibody-dependent enhancement of dengue virus infection. J. Immunol. 2006, 176, 2825-2832.

74. Yu, I.M.; Zhang, W.; Holdaway, H.A.; Li, L.; Kostyuchenko, V.A.; Chipman, P.R.; Kuhn, R.J.; Rossmann, M.G.; Chen, J. Structure of the immature dengue virus at low $\mathrm{pH}$ primes proteolytic maturation. Science 2008, 319, 1834-1837.

75. Rodenhuis-Zybert, I.A.; van der Schaar, H.M.; da Silva Voorham, J.M.; van der Ende-Metselaar, H.; Lei, H.Y.; Wilschut, J.; Smit, J.M. Immature dengue virus: A veiled pathogen? PLoS Pathog. 2010, 6, e1000718.

76. Keelapang, P.; Sriburi, R.; Supasa, S.; Panyadee, N.; Songjaeng, A.; Jairungsri, A.; Puttikhunt, C.; Kasinrerk, W.; Malasit, P.; Sittisombut, N. Alterations of pr-M cleavage and virus export in pr-M junction chimeric dengue viruses. J. Virol. 2004, 78, 2367-2381.

77. Behrens, S.E.; Isken, O. Cis-and Trans-acting Determinants of Flaviviridae Replication. In Molecular Biology of the Flavivirus, Kalitzky, M., Borowski, P., Eds.; Horizon Bioscience: Norfolk, UK, 2006; p. 101.

78. Lai, M.M. Cellular factors in the transcription and replication of RNA genomesÑ a parallet to DNA-dependent RNA transcription. Virology 1998, 244, 1-12.

79. Valdes, K.; Alvarez, M.; Pupo, M.; Vazquez, S.; Rodriguez, R.; Guzman, M.G. Human Dengue antibodies against structural and nonstructural proteins. Clin. Diagn. Lab. Immunol. 2000, 7 , 856-857. 
80. Churdboonchart, V.; Bhamarapravati, N.; Peampramprecha, S.; Sirinavin, S. Antibodies against dengue viral proteins in primary and secondary dengue hemorrhagic fever. Am. J. Trop. Med. Hyg. 1991, 44, 481-493.

81. Se-Thoe, S.Y.; Ng, M.M.; Ling, A.E. Retrospective study of Western blot profiles in immune sera of natural dengue virus infections. J. Med. Virol. 1999, 57, 322-330.

82. Cherrier, M.V.; Kaufmann, B.; Nybakken, G.E.; Lok, S.M.; Warren, J.T.; Chen, B.R.; Nelson, C.A.; Kostyuchenko, V.A.; Holdaway, H.A.; Chipman, P.R.; et al. Structural basis for the preferential recognition of immature flaviviruses by a fusion-loop antibody. Embo J. 2009, 28, 3269-3276.

83. Kouri, G.P.; Guzman, M.G.; Bravo, J.R. Why dengue haemorrhagic fever in Cuba? 2. An integral analysis. Trans. R. Soc. Trop. Med. Hyg. 1987, 81, 821-823.

84. Rico-Hesse, R. Dengue virus evolution and virulence models. Clin. Infect. Dis. 2007, 44, 1462-1466.

85. Halstead, S.B. Dengue. Lancet 2007, 370, 1644-1652.

86. Guzman, M.G.; Kouri, G.; Bravo, J.; Valdes, L.; Vazquez, S.; Halstead, S.B. Effect of age on outcome of secondary dengue 2 infections. Int. J. Infect. Dis. 2002, 6, 118-124.

87. Halstead, S.B.; Streit, T.G.; Lafontant, J.G.; Putvatana, R.; Russell, K.; Sun, W.; Kanesa-Thasan, N.; Hayes, C.G.; Watts, D.M. Haiti: Absence of dengue hemorrhagic fever despite hyperendemic dengue virus transmission. Am. J. Trop. Med. Hyg. 2001, 65, 180-183.

88. Bravo, J.R.; Guzman, M.G.; Kouri, G.P. Why dengue haemorrhagic fever in Cuba? 1. Individual risk factors for dengue haemorrhagic fever/dengue shock syndrome (DHF/DSS). Trans. R. Soc. Trop. Med. Hyg. 1987, 81, 816-820.

89. Sierra, B.; Alegre, R.; Perez, A.B.; Garcia, G.; Sturn-Ramirez, K.; Obasanjo, O.; Aguirre, E.; Alvarez, M.; Rodriguez-Roche, R.; Valdes, L.; et al. HLA-A, -B, -C, and -DRB1 allele frequencies in Cuban individuals with antecedents of dengue 2 disease: Advantages of the Cuban population for HLA studies of dengue virus infection. Hum. Immunol. 2007, 68, 531-540.

90. Garcia, G.; Sierra, B.; Perez, A.B.; Aguirre, E.; Rosado, I.; Gonzalez, N.; Izquierdo, A.; Pupo, M.; Ruiz, A.; Diaz, D.; et al. Asymptomatic dengue infection in a Cuban population confirms the protective role of the RR variant of the FcyRIIa polymorphism. Am. J. Trop. Med. Hyg. 2010, 82, 1153-1156.

91. Sierra, B.; Kouri, G.; Guzman, M.G. Race: A risk factor for dengue hemorrhagic fever. Arch. Virol. 2007, 152, 533-542.

92. Halstead, S.B. Overview and History. In Dengue; Pasvol, G., Hoffman, S.L., Eds.; Imperial College Press: Covent Garden, London, UK, 2008; Volume 5, pp. 1-28.

93. Yamanaka, A.; Kosugi, S.; Konishi, E. Infection-enhancing and -neutralizing activities of mouse monoclonal antibodies against dengue type 2 and 4 viruses are controlled by complement levels. J. Virol. 2008, 82, 927-937.

94. Balsitis, S.J.; Williams, K.L.; Lachica, R.; Flores, D.; Kyle, J.L.; Mehlhop, E.; Johnson, S.; Diamond, M.S.; Beatty, P.R.; Harris, E. Lethal antibody enhancement of dengue disease in mice is prevented by Fc modification. PLoS Pathog. 2010, 6, e1000790. 
95. Mehlhop, E.; Ansarah-Sobrinho, C.; Johnson, S.; Engle, M.; Fremont, D.H.; Pierson, T.C.; Diamond, M.S. Complement protein C1q inhibits antibody-dependent enhancement of flavivirus infection in an IgG subclass-specific manner. Cell Host Microbe 2007, 2, 417-426.

96. Boonnak, K.; Slike, B.M.; Burgess, T.H.; Mason, R.M.; Wu, S.J.; Sun, P.; Porter, K.; Rudiman, I.F.; Yuwono, D.; Puthavathana, P.; et al. Role of dendritic cells in antibody-dependent enhancement of dengue virus infection. J. Virol. 2008, 82, 3939-3951.

(C) 2010 by the authors; licensee MDPI, Basel, Switzerland. This article is an open access article distributed under the terms and conditions of the Creative Commons Attribution license (http://creativecommons.org/licenses/by/3.0/). 